\title{
Ibuprofen delivered by poly(lactic-co-glycolic acid) (PLGA) nanoparticles to human gastric cancer cells exerts antiproliferative activity at very low concentrations
}

This article was published in the following Dove Press journal:

International Journal of Nanomedicine

8 November 2012

Number of times this article has been viewed

\author{
Patrizia Bonelli ${ }^{1}$ \\ Franca M Tuccillo' \\ Antonella Federico ${ }^{5}$ \\ Maria Napolitano ${ }^{2}$ \\ Antonella Borrelli' \\ Daniela Melisi ${ }^{6}$ \\ Maria G Rimolí \\ Raffaele Palaia ${ }^{3}$ \\ Claudio Arra ${ }^{4}$ \\ Francesco Carinci ${ }^{7}$ \\ 'Laboratory of Molecular Biology and \\ Viral Oncogenesis; 'Department of \\ Clinical Immunology; ${ }^{3}$ Department \\ of Gastrointestinal-Hepatobiliary- \\ Pancreatic Cancer Oncology Surgery; \\ ${ }^{4}$ Animal Facility, National Cancer \\ Institute G Pascale, Naples, Italy; \\ ${ }^{5}$ Microtech Laboratory, Naples, Italy; \\ ${ }^{6}$ Pharmaceutical and Toxicological \\ Chemistry Department, School of \\ Pharmacy, University "Federico II", \\ Naples, Italy; ${ }^{7}$ Department of \\ Maxillofacial Surgery, University \\ of Ferrara, Ferrara, Italy
}

Correspondence: Patrizia Bonelli Laboratory of Molecular Biology and Viral Oncogenesis, National Cancer Institute G Pascale,Via Mariano Semmola, $80 \mathrm{I} 3 \mathrm{I}-$ Naples, Italy

$\mathrm{Tel}+3908 \mathrm{I} 5903270$

Fax +3908I 5903803

Email patrizia.bonelli@virgilio.it
Purpose: Epidemiological, clinical, and laboratory studies have suggested that ibuprofen, a commonly used nonsteroidal anti-inflammatory drug, inhibits the promotion and proliferation of certain tumors. Recently, we demonstrated the antiproliferative effects of ibuprofen on the human gastric cancer cell line MKN-45. However, high doses of ibuprofen were required to elicit these antiproliferative effects in vitro. The present research compared the antiproliferative effects of ibuprofen delivered freely and released by poly(lactic-co-glycolic acid) (PLGA) nanoparticles (NPs) in MKN-45 cells.

Methods: MKN-45 human gastric adenocarcinoma cells were treated with ibuprofen-loaded PLGA NPs. The proliferation of MKN-45 cells was then assessed by cell counting. The uptake of NPs was imaged by fluorescence microscopy and flow cytometry. The release of ibuprofen from ibuprofen-loaded PLGA NPs in the cells was evaluated by gas chromatography-mass spectrometry.

Results: Dramatic inhibition of cellular proliferation was observed in cells treated with ibuprofen-loaded PLGA NPs versus those treated with free ibuprofen at the same concentration. The localization of NPs was cytoplasmic. The initiation of ibuprofen release was rapid, commencing within 2 hours, and then increased slowly over time, reaching a maximum concentration at 24 hours. The inhibition of proliferation was confirmed to be due to the intracellular release of ibuprofen from the NPs. Using PLGA NPs as carriers, ibuprofen exerted an antiproliferative activity at concentrations $>100$ times less than free ibuprofen, suggesting greater efficiency and less cellular toxicity. In addition, when carried by PLGA NPs, ibuprofen more quickly induced the expression of transcripts involved in proliferation and invasiveness processes.

Conclusion: Ibuprofen exerted an antiproliferative effect on MKN-45 cells at low concentrations. This effect was achieved using PLGA NPs as carriers of low doses of ibuprofen.

Keywords: nonsteroidal anti-inflammatory drug (NSAID), proliferation, uptake, MKN-45 cells

\section{Introduction}

Numerous epidemiological, clinical, and laboratory studies have suggested that ibuprofen, a commonly used nonsteroidal anti-inflammatory drug, inhibits the promotion and proliferation of some tumors. ${ }^{1-8}$ Recently, we demonstrated the antiproliferative effects of ibuprofen on the human gastric cancer cell line MKN-45. ${ }^{9}$ Ibuprofen, at concentrations of $400-800 \mu \mathrm{M}$, significantly inhibited cellular proliferation in a time- and concentration-dependent manner. 
Using microarray technology, we studied changes in gene expression profiles after ibuprofen treatment, over time. Ibuprofen exerted its antiproliferative actions through cell-cycle control and the induction of apoptosis. However, high doses of ibuprofen were required to elicit these antiproliferative effects. When we used lower concentrations of ibuprofen $(<400 \mu \mathrm{M})$, there were no evident effects on cell proliferation. In recent years, nanoparticles (NPs) have piqued the interest of the medical community for use in cancer diagnosis and treatment, and as delivery vectors for biologic or pharmacologic agents. ${ }^{10-13}$ One of the advantages of NPs is that water-insoluble therapeutics can be transported more efficiently in the aqueous physiological environment when formed into stable NPs. ${ }^{14}$ Ibuprofen is a propionic acid derivative that has the disadvantage of low water solubility.

Over the years, a variety of natural and synthetic polymers have been explored for the preparation of NPs; specifically, poly(lactic acid), poly(glycolic acid), and their copolymer, poly(lactic-co-glycolic acid) (PLGA), have been extensively investigated because of their biocompatibility and biodegradability. PLGA particles, in particular, have been widely studied as therapeutic delivery vehicles because they are biodegradable ${ }^{15}$ and biocompatible. ${ }^{16-18}$ Some study has been undertaken to investigate hydrophobic drug incorporation into PLGA NPs. ${ }^{19,20}$ Because of their hydrophobic nature, it is relatively easy to entrap hydrophobic drugs into PLGA NPs. Polymeric NPs have advantages with respect to other drug delivery systems, such as greater stability during storage..$^{21}$ Biodegradable NPs made from PLGA have been extensively used as drug delivery systems for a variety of drugs. ${ }^{22,23}$ PLGA microparticles are already approved for establishing the sustained release of leuprolide (Lupron Depot $^{\circledR}$, Abbott Laboratories, IL) and triptorelin (Trelstar ${ }^{\circledR}$, Watson Pharmaceuticals, Parsipanny, NJ) in cancer therapy.

In a previous study, we analyzed the gene expression profiles of MKN-45 cells treated with free ibuprofen at various concentrations and over a time course. ${ }^{9}$ We observed that after 24 hours of treatment, Angiopoietin-like protein 4 (ANGPTL4) was upregulated and the expression levels were dependent on ibuprofen concentration (data not shown). This result was also observed in a parallel study conducted on prostate cancer cells treated with nonsteroidal antiinflammatory drugs, including ibuprofen. ${ }^{24}$ Recent studies have shown that overexpression of ANGPTL4, also known as peroxisome proliferator-activated receptor gamma, inhibits the proliferation of cancer cells in vitro and growth of tumors in vivo. ${ }^{25,26}$
In this study, biodegradable NPs made from PLGA were chosen as carriers of ibuprofen. The aim of this study was to investigate whether low concentrations of ibuprofen exert an antiproliferative effect when delivered by PLGA-based NPs in the human gastric cancer cell line MKN-45, and the effect on the expression of ANGPTL4 gene.

\section{Material and methods Maintenance of cell line}

MKN-45 human gastric adenocarcinoma cells were obtained from the German Collection of Microorganisms and Cell Cultures (Leibniz Institute DSMZ, Braunschweig, Germany). This cell line was originally derived from a poorly differentiated medullary adenocarcinoma. The cells were characterized for the presence of cytokeratin proteins and confirmed as being of human origin by detection of aspartate aminotransferase using an isoelectric focusing technique. All of the cells were mycoplasma- and virus-negative. Cells were grown as monolayer cultures in RPMI 1640 medium supplemented with $20 \%$ fetal bovine serum and $2 \mathrm{mM}$ glutamine. The cells were incubated at $37^{\circ} \mathrm{C}$ in a humidified atmosphere of $95 \%$ air $/ 5 \% \mathrm{CO}_{2}$ and subcultured twice weekly. All tissue culture reagents (L-Glutamine $200 \mathrm{mM}$ code BE17-605E; RPMI1640, code BE12-167F; fetal bovine serum code DE14-802F; trypsin-EDTA, code BE17-161E) were obtained from Lonza (Basel, Switzerland). Ibuprofen was purchased from MP Biomedicals (MP Biomedicals, Illkirch Cedex, France). The ibuprofen was prepared fresh in dimethyl sulfoxide (DMSO) and sterilized before addition to the cells. Control cells were treated with equivalent amounts of DMSO.

\section{Ibuprofen-loaded NPs}

Ibuprofen-loaded fluorescent PLGA (50:50) NPs were purchased from Phosphorex, Inc (Hopkinton, MA) at 5.4\% ibuprofen/100 mg NPs. Briefly, ibuprofen, PLGA and fluorescent dye were dissolved in acetone. The acetone solution was added dropwise to a $1 \%$ polyvinyl alcohol solution with magnetic stirring, using a syringe pump. The resulting nanoparticle suspension was centrifuged, and washed three times with distilled water. After washing, the NPs were lyophilized and stored in a dessicator. The lyophilized NPs were reconstituted in distilled water, and sonicated to ensure complete dispersion, and the size of the NPs was measured on a laser diffraction particle size analyzer (LS 320; Beckman-Coulter, Brea, CA).

\section{In vitro release of ibuprofen}

In vitro studies of ibuprofen release from the NPs under investigation were carried out as follows: $19 \mathrm{mg}$ of 
the sample was trapped in a tea bag and kept in a beaker with $40 \mathrm{~mL}$ of distilled water at $37^{\circ} \mathrm{C}$ for 24 hours. Every 30 minutes, $3 \mathrm{~mL}$ of the solution was withdrawn, and ibuprofen release was measured by means of ultraviolet-visible spectroscopy (UV Mini-1240; Shimadzu Scientific Instruments, Columbia, MD). Absorbance values were taken at a wavelength of $\lambda=221 \mathrm{~nm}$, at which ibuprofen in distilled water shows an absorbance maximum. After each measurement, the withdrawn sample was poured back into the beaker. The experiment was performed in triplicate. A calibration curve was determined by measurements of absorbance versus ibuprofen concentration between 0 and $1 \mathrm{mM}$ as parameters. Within this interval, the calibration curve fit the Lambert and Beers' law: $A=6.6403 \times \mathrm{C}$, where $\mathrm{A}$ is the absorbance and $\mathrm{C}$ is the concentration ( $\mathrm{mM})$.

\section{In vitro proliferation studies}

The proliferation of MKN-45 cells treated with ibuprofenloaded PLGA NPs was assessed by cell counting. Briefly, cells were seeded in a 24 -well plate at a density of $5 \times 10^{4}$ cells/well, and allowed to adhere for 24 hours prior to the assay. The cells were exposed to either PLGA NPs or ibuprofen-loaded PLGA NPs at $37^{\circ} \mathrm{C}$ in serum-free medium for 2 hours. The cells were washed three times with phosphate-buffered saline (PBS), and then fresh medium with serum (20\%) was added. After 24-48 hours of incubation, the cells were detached by means of trypsin-EDTA solution and counted on a hemocytometer. Cell viability was assessed via a Trypan blue exclusion assay. To compare the effects of ibuprofen-loaded PLGA NPs versus free ibuprofen, the cells were also exposed to ibuprofen solution $(200 \mu \mathrm{M})$ under the same conditions. The antiproliferative effects of ibuprofenloaded PLGA NPs and free ibuprofen were presented as cell no $\%$ of control, calculated as follows:

Cell no $\%$ of control $=$ Cell no treated $_{\text {Cell no }} /$ control $\times 100$

where Cell no treated $_{\text {was }}$ the number of cells after exposure to ibuprofen loaded PLGA NPs and Cell no ${ }_{\text {control }}$ was the number of cells after incubation with culture medium alone or culture medium plus DMSO.

\section{Clonogenic assay}

Cells were treated with $200 \mu \mathrm{M}$ ibuprofen, ibuprofen-loaded PLGA NPs, or PLGA NPs, or ibuprofen for 24 hours, as described above. The cells were trypsinized and counted then, 50 cells were plated in triplicate in 6-well plates for the clonogenic assay. The colonies were stained with crystal violet after 12 days, and colonies of $>50$ cells were counted.

\section{Nanoparticle uptake by tumor cells}

A total of $2 \times 10^{4} \mathrm{MKN}-45$ cells were seeded on Millicell EZ slides (Code PEZGS0416; Millipore Corporation, Billerica, MA) with $0.3 \mathrm{~mL}$ of RPMI 1640 supplemented with $20 \% \mathrm{FBS}$, and allowed to adhere at $37^{\circ} \mathrm{C}$ with $5 \% \mathrm{CO}_{2}$ for 24 hours prior to assay. The medium was then replaced with fresh medium without serum before the ibuprofen-loaded PLGA NPs were added. After 2 hours of incubation, the cell monolayers were rinsed three times with PBS buffer to remove excess NPs, and were incubated with complete medium. NP uptake was then imaged by fluorescence microscopy. Briefly, slides were washed twice with PBS, fixed with $1 \%$ paraformaldehyde in PBS, washed three times with PBS for 5 minutes, treated for 7 minutes with 4',6-diamidino-2-phenylindole (DAPI; Invitrogen Corporation, Carlsbad, CA), washed three times with PBS, and mounted for microscopy with glycerol.

In addition, a flow cytometry assay was performed. A total of $5 \times 10^{4} \mathrm{MKN}-45$ cells were seeded in a 24-well plate with $0.5 \mathrm{~mL}$ RPMI 1640 supplemented with 20\% FBS, and allowed to adhere at $37^{\circ} \mathrm{C}$ with $5 \% \mathrm{CO}_{2}$ for 24 hours prior to assay. The medium was then replaced with fresh medium without serum prior to adding ibuprofen-loaded PLGA NPs. After 2 hours of incubation, the cell monolayers were rinsed three times with PBS buffer to remove excess NPs, and incubated with complete medium. Cells were collected and washed twice with cold PBS. The pellet was resuspended in FACSFlow Sheath Fluid (BD Biosciences, Franklin Lakes, NJ), and analyzed with a FACSCanto II cytometer (BD Biosciences). For each sample, $>20,000$ cells were analyzed using FACSDiva software (Version 6.0, BD Biosciences).

\section{Release of ibuprofen in cell lysates from NPs}

The release of ibuprofen from ibuprofen-loaded PLGA NPs was evaluated by gas chromatography-mass spectrometry. To analyse the time of ibuprofen release into the cells from ibuprofen-loaded PLGA NPs, cells were collected, washed twice with PBS, and lysed with radioimmunoprecipitation assay buffer containing $50 \mathrm{mM}$ Tris- $\mathrm{HCl}, \mathrm{pH} 8.0,150 \mathrm{mM}$ sodium chloride, $1 \%$ NP-40, $0.5 \%$ sodium deoxycholate, $0.1 \%$ sodium dodecyl sulfate (Sigma-Aldrich, St Louis, MO), and protease inhibitors (Sigma-Aldrich). The cells were incubated on ice for 10 minutes, and then centrifuged at $8000 \times g$ at $4^{\circ} \mathrm{C}$ for 10 minutes to pellet the cell debris. A subsequent centrifugation at $20,000 \times g$ was performed to collect NPs. The lysates were frozen at $-80^{\circ} \mathrm{C}$ until analysis. The release of ibuprofen into the cell lysates was then quantified by 
gas chromatography-mass spectrometry. The samples were extracted in hexane and trimethylsilylated in $100 \mu \mathrm{L}$ N,O-bis(trimethylsilyl) acetamide (TMSA, Sigma-Aldrich) at $80^{\circ} \mathrm{C}$ for 45 minutes. The samples were dried under nitrogen and dissolved in $10 \mu \mathrm{L}$ hexane, and the supernatants were used for analysis. The samples were analyzed by gas chromatography-mass spectrometry on an Agilent instrument (Agilent 5890; Agilent Technologies, Santa Clara, CA) under the following conditions: capillary column (ZB-5; Phenomenex Inc, Torrance, CA); $30 \mathrm{~m} \times 0.25 \mathrm{~mm}$ ID; flow rate, $1 \mathrm{~mL} / \mathrm{min}$; helium as carrier gas) with a temperature program of $120^{\circ} \mathrm{C}$ for 3 minutes, which then increased from $100^{\circ} \mathrm{C}$ to $280^{\circ} \mathrm{C}$ at $20^{\circ} \mathrm{C} / \mathrm{min}$.

\section{Flow cytometric analysis of DNA content}

For the monoparametric cell-cycle analysis, we collected the treated and control cells, washed them in PBS, and fixed them with cold $70 \%$ ethanol at $4^{\circ} \mathrm{C}$ for $\geq 24$ hours. Then, $2 \times 10^{6}$ cells were washed twice in PBS, and incubated with $2 \mathrm{~mL}$ of $20 \mu \mathrm{g} / \mathrm{mL}$ propidium iodide (Sigma-Aldrich) in PBS containing 0.002\% Nonidet P40 (Roche Applied Science, Penzberg, Germany) and $12.5 \mu \mathrm{g} / \mathrm{mL}$ RNase A (Sigma-Aldrich) at RT for $\geq 60$ minutes. For each sample, $>50,000$ cells were analyzed for DNA content by a FACSCanto II flow cytometer (BD Biosciences). The DNA histogram was analyzed for cell-cycle progression using ModFit LT v 3.0 software (Verity Software House, Topsham, ME).

\section{RNA isolation}

The RNeasy Plus Mini Kit (Qiagen, Hilden, Germany) was used to extract total RNA from MKN-45 cells treated with either ibuprofen-loaded PLGA NPs or free ibuprofen (200 and $800 \mu \mathrm{M}$ ) for 2 hours. RNA was also isolated from untreated control MKN-45 cells. Contaminating genomic DNA was removed using gDNA Eliminator spin columns (Qiagen). The purity and integrity of the isolated RNA were determined using a spectrophotometer, denaturing agarose gel electrophoresis, and an Agilent 2100 Bioanalyser (Agilent Technologies). The RNA integrity number (RIN) values of the isolated RNA were nearly 10 .

\section{Real-time PCR assay}

Total RNA isolated from cells as described above was used for cDNA synthesis. Real-time quantitative RT-PCR analyses for ANGPTL4 were performed (CFX 96 RealTime PCR Detection System; Bio-Rad Laboratories, Inc, Hercules, CA) using Power SYBR Green PCR Master Mix
(Applied Biosystems, Foster City, CA) with the thermocycler conditions recommended by the manufacturer. All reactions were performed in a total volume of $25 \mu \mathrm{L}$ containing $50 \mathrm{ng}$ of cDNA and $2.5 \mu \mathrm{L}$ of the $10 \times$ QuantiTect Primer (Qiagen). Reactions were carried out in triplicate on three independent sets of RNA. The QuantiTect Primers were bioinformatically validated to detect RNA only, provided that no pseudogenes with high cDNA similarity existed or that the transcript was not derived from a single-exon gene. Negative controls (no cDNA added) were processed under the same conditions as the experimental samples. Human glyceraldehyde 3-phosphate dehydrogenase was used as an endogenous control to normalize target gene expression, and correct for experimental variation. Relative gene expression was calculated using the method described by Livak and Schmittgen ${ }^{27}$ and expressed as the fold change compared with control cells treated only with culture medium or culture medium plus DMSO.

\section{Statistical analysis}

All data are shown as the mean $\pm \mathrm{SD}$. Student's $t$-test was used to determine the statistical significance of the observed differences.

\section{Results}

\section{In vitro release of ibuprofen}

Figure 1 shows the time-dependent release rate of ibuprofen from the NPs in distilled water. It was observed that the anti-inflammatory agent was released in a relatively rapid manner during the first hour and was completely released within 150 minutes.

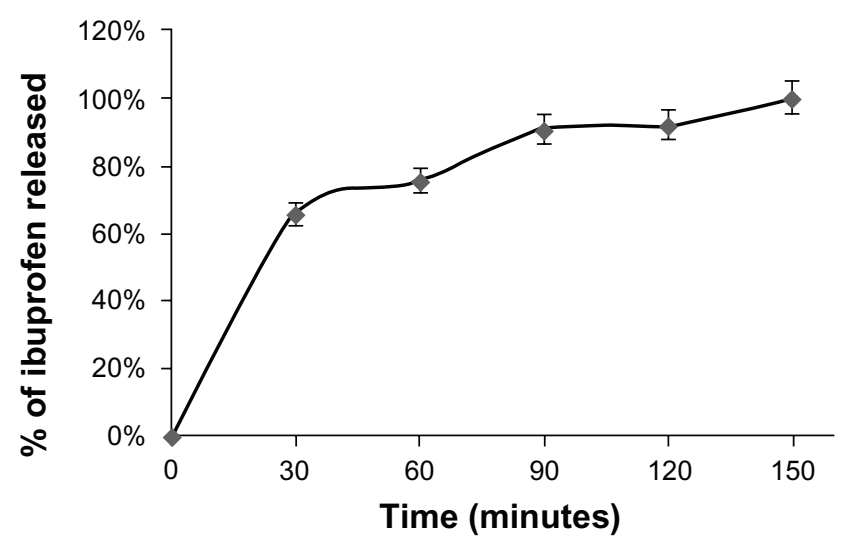

Figure I Percentage of ibuprofen released from nanoparticles versus time. Notes: In vitro release of ibuprofen from nanoparticles was assessed as described in the Materials and methods. Measurements were carried out every 30 minutes by means of UV-VIS spectroscopy with a Shimadzu UV mini-1240. The results are presented as the percentage of ibuprofen released over time. The experiment was performed in triplicate. 


\section{Effects of ibuprofen-loaded-PLGA NPs on gastric cancer cell proliferation}

Human MKN-45 cells showed a dramatic inhibition of cellular proliferation when treated with ibuprofen-loaded PLGA NPs versus free ibuprofen at the same concentration. A slight effect on proliferation was observed in cells treated with NPs alone but was not significant (Figure 2). The antiproliferative effects persisted after 48 hours without further addition of NPs. Inhibition of proliferation was confirmed to be due to the intracellular release of ibuprofen from the NPs.

\section{Clonogenic survival of ibuprofen-treated MKN-45 cells}

The plating efficiency of the control cells was $0.98 \pm 0.02$ after 24 hours. The surviving fraction of cells treated with $200 \mu \mathrm{M}$ of ibuprofen at 24 hours was $1.23 \pm 0.01$ compared with the control. The surviving fraction of cells treated with ibuprofen-loaded PLGA NPs at 24 hours was $0.94 \pm 0.01$ compared with the control. The surviving fraction of cells treated with PLGA NPs at 24 hours was $0.98 \pm 0.01$ compared with the control.

\section{Proliferation of MKN-45 cells}

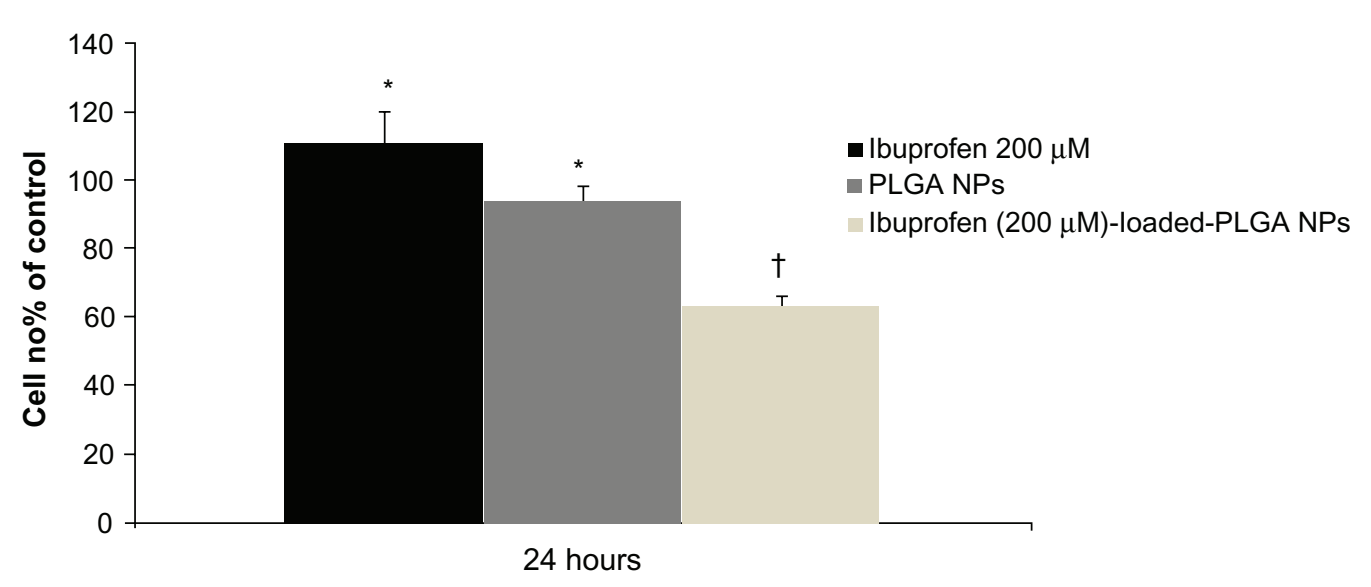

Time

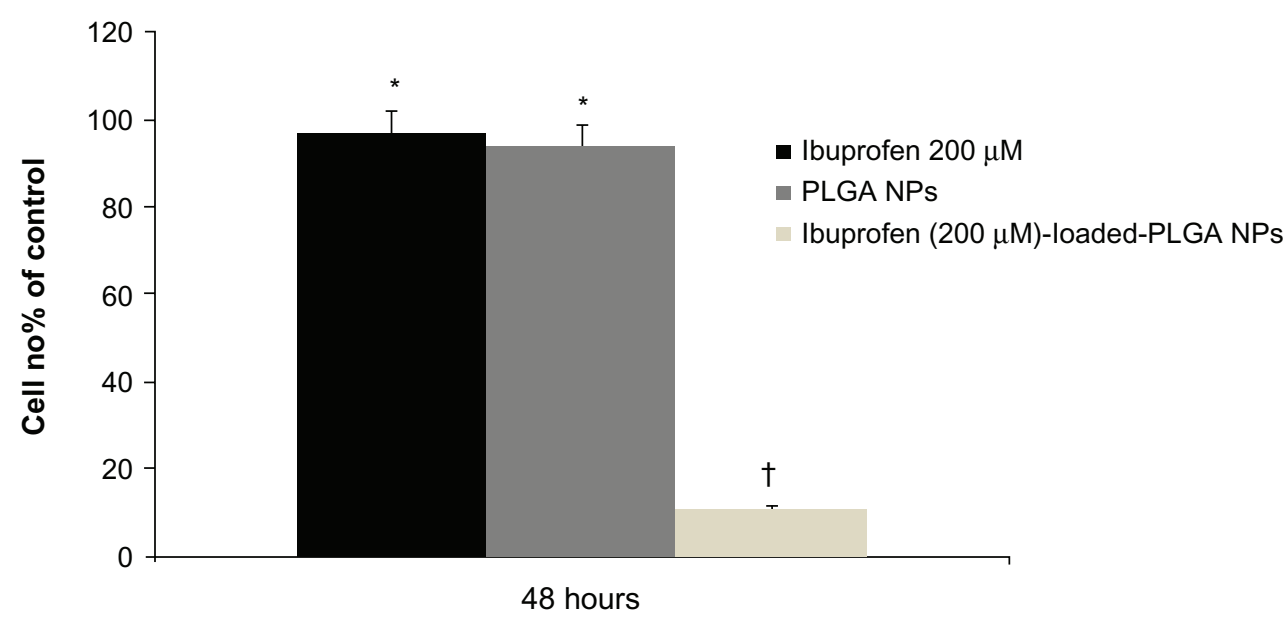

Time

Figure 2 Effect of ibuprofen, PLGA NPs and ibuprofen-loaded PLGA NPs on cell proliferation.

Notes: MKN-45 cells $\left(5 \times 10^{4}\right.$ cells/well) were seeded in 24-well plates and incubated overnight. The cells were then treated with ibuprofen, ibuprofen-loaded PLGA NPs, or PLGA NPs for 24 hours. The cells were harvested and counted. Viability was determined by Trypan blue dye exclusion. Cell growth was calculated by averaging cell counts and as expressed as the percentage of the control, represented by MKN-45 cells grown in culture medium alone or culture medium with DMSO (I00\%). The mean values from three independent experiments performed in duplicate are presented. Ibuprofen significantly inhibited the proliferation of MKN-45 cells only in cells treated with ibuprofen-loaded PLGA NPs. Bars, SD; $* P<0.5$; ${ }^{\dagger} P<0.005$; Student's $t$-test.

Abbreviations: PLGA, poly(lactic-co-glycolic acid); NPs, nanoparticles; DMSO, dimethyl sulfoxide. 


\section{Effects of serum-free medium conditions on cell cycle}

We treated MKN-45 cells with ibuprofen-loaded PLGA NPs in serum-free conditions for 2 hours, after which the cells were rinsed three times with PBS buffer to remove excess NPs, and incubated with complete medium. We analyzed the distribution of cells in each cell cycle phase to study whether serum deprivation for 2 hours was involved in inhibiting cell proliferation. Treatment under serum-free conditions did not block cells in phase $\mathrm{G}_{0} / \mathrm{G}_{1}$ of the cell cycle (Table 1), suggesting that the inhibition of proliferation was due only to the release of ibuprofen from NPs.

\section{Uptake of PLGA NPs by MKN-45 cells}

Figure 3 shows the cellular uptake of fluorescent NPs. The results clearly demonstrate that the localization of the NPs was cytoplasmic. To assess the percentage of cells incorporating NPs, we performed flow cytometric analysis. Figure 4 shows typical fluorescence histograms (a), and the percentage of fluorescent cells (b), at different time intervals. After 24 hours, almost all of the cells were fluorescent; the cells remained fluorescent after 48 hours.

\section{Release of ibuprofen from PLGA NPs in cells}

To investigate the relationship between the antiproliferative effects of ibuprofen and the drug concentration in cells, the cellular release of ibuprofen from ibuprofen-loaded PLGA NPs was determined in MKN-45 cell lysates after 2,4 , and 24 hours of exposure. Centrifugation at 20,000 $\times g$ eliminated NPs from the cell lysates. The ibuprofen content in the cell lysate increased rapidly in the first 2 hours and then, increased slowly over time, reaching a maximum at 24 hours (Table 2). However, the amount of ibuprofen found in the cell lysates was approximately $0.3 \mathrm{nmol}$, corresponding to $<1 \%$ of the initially added ibuprofen-loaded PLGA NPs. Ibuprofen-loaded PLGA NPs exerted antiproliferative

Table I Effect of serum-free conditions on cell cycle in MKN45 cells

\begin{tabular}{llll}
\hline Treatment & $\begin{array}{l}\mathbf{G}_{\mathbf{0}} / \mathbf{G}_{\mathbf{1}} \\
(\%)\end{array}$ & $\begin{array}{l}\mathbf{S} \\
\mathbf{( \% )}\end{array}$ & $\begin{array}{l}\mathbf{G}_{2} / \mathbf{M} \\
(\%)\end{array}$ \\
\hline Control & $49.0 \pm 2.0$ & $37.2 \pm 1.6$ & $13.8 \pm 1.7$ \\
Serum free medium & $49.1 \pm 1.3$ & $37.3 \pm 2.5$ & $13.6 \pm 1.1$ \\
\hline
\end{tabular}

Notes: Values represent the mean \pm SD of four independent experiments performed in duplicate; $P<0.5$; Student's $t$-test.

Abbreviations: $G_{0} / G_{1}$, phase of the cell cycle; $S$, phase of the cell cycle; $G_{2} M$, phase of the cell cycle.

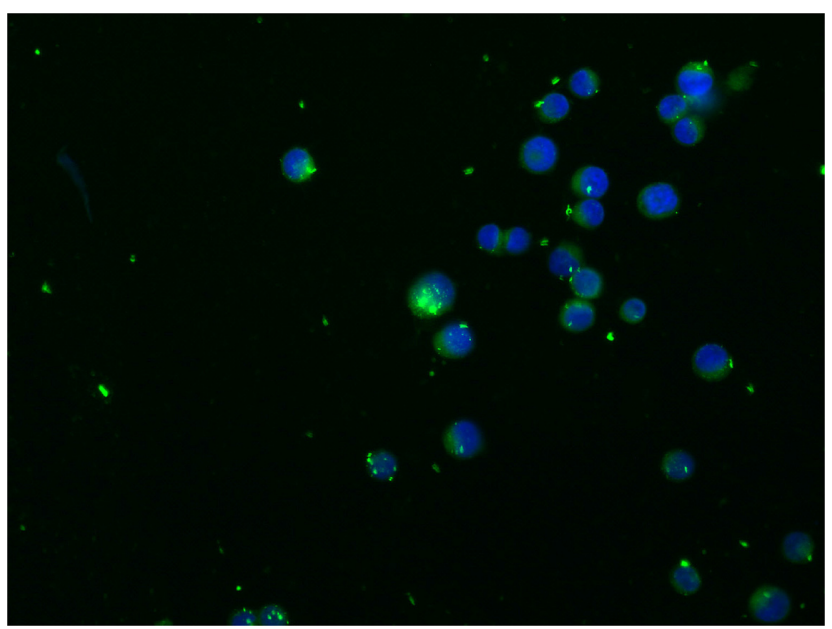

Figure 3 Nanoparticle uptake by MKN-45 cells revealed by fluorescence microscopy. Notes: Intracellular detection of ibuprofen-loaded PLGA NPs. Cells were imaged using a Leica fluorescence microscope at $40 \times$ objective magnification. A total of $2 \times 10^{4} \mathrm{MKN}-45$ cells were seeded on Millicell EZ slides as described in the Materials and methods and treated with ibuprofen-loaded PLGA NPs for 2 hours. The nuclei were stained with DAPI. The localization of NPs was intracellular.

Abbreviations: PLGA, poly(lactic-co-glycolic acid); NPs, nanoparticles; DAPI, 4',6diamidino-2-phenylindole.

activity at $5 \mu \mathrm{M} / \mathrm{L}$, that is, at a concentration $>100$ times lower than that of free ibuprofen.

\section{ANGPTL4 mRNA expression}

To verify the effect of treatment with ibuprofen-loaded PLGA NPs and free ibuprofen, we analyzed changes in the expression of the transcript for ANGPTL4 by real-time PCR. Figure 5 presents the real-time PCR output from MKN45 cells treated for 2 hours with ibuprofen-loaded PLGA NPs and free ibuprofen at 200 and $800 \mu \mathrm{M}$. We observed increased mRNA levels after 2 hours of treatment with ibuprofen-loaded PLGA NPs; a fold change of 10.3 with respect to the control cells was observed, while with free ibuprofen at 200 and $800 \mu \mathrm{M}$, the fold change was 0.15 and 1.70 , respectively, compared to control cells, measured by the number cells grown in culture medium alone or in culture medium plus DMSO. Previously we observed increased ANGPTL4 mRNA levels in MKN-45 cells treated for 24 hours with free ibuprofen at $800 \mu \mathrm{M}$, which was indicated by a fold change of 22.20 with respect to the control cells (data not shown).

\section{Discussion}

The primary purpose of this work was to study whether ibuprofen carried by PLGA NPs in gastric cancer cells exerted antiproliferative effects at low concentrations. We previously demonstrated the antiproliferative activity of ibuprofen on MKN-45 cells. ${ }^{9}$ However, high doses of ibuprofen were required to elicit these antiproliferative effects. Previous 


\section{A}
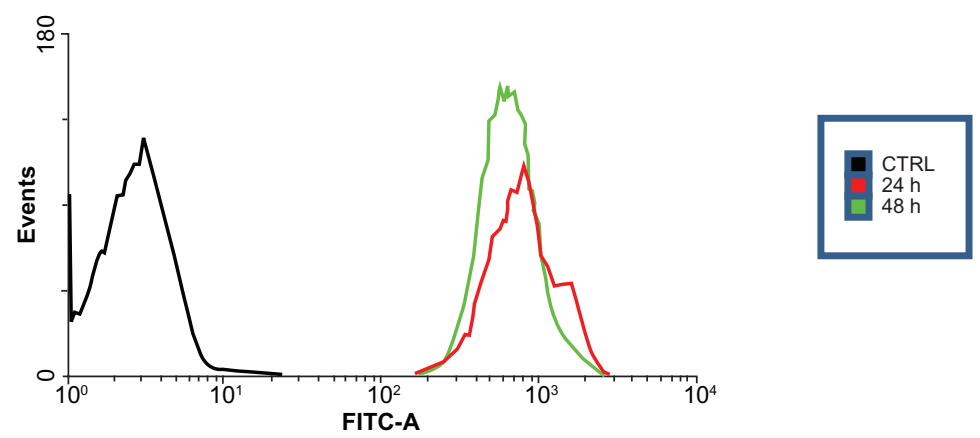

B

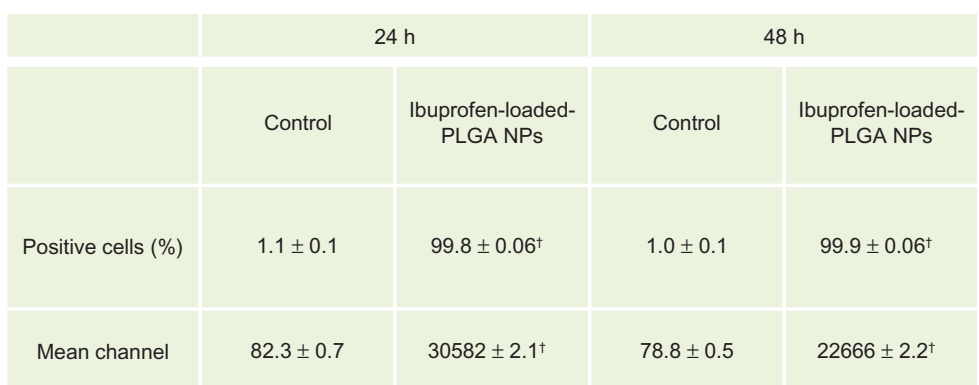

Figure 4 Nanoparticle uptake by MKN-45 cells revealed by flow cytometry. A total of $5 \times 10^{4} \mathrm{MKN}-45$ cells were seeded in a 24 -well plate for 24 hours prior to assay, The medium was then replaced with fresh RPMI 1640 without serum before ibuprofen-loaded PLGA NPs were added. After 2 hours of incubation, the cell monolayers were rinsed three times with PBS buffer to remove excess NPs and incubated with complete medium. NP uptake was verified by flow cytometry. The cells were collected and washed twice with cold PBS. The pellets were resuspended in FACSFlow Sheath Fluid and analyzed by a FACSCanto II cytometer. For each sample, $>20,000$ cells were analyzed by FACSDiva software. Typical fluorescence histograms (A) and the percentage of fluorescent cells (B) at different time intervals are shown. Nearly I00\% of the cells were fluorescent at 24 and 48 hours.

Notes: Values represent the means of three independent experiments performed in triplicate; $\left({ }^{\dagger} P<0.005\right.$; Student’s $t$-test $)$.

Abbreviations: PLGA, poly(lactic-co-glycolic acid); NPs, nanoparticles; PBS, phosphate-buffered saline.

experiments performed with lower concentrations of ibuprofen in the $400-800 \mu \mathrm{M}$ range on MKN-45 cells showed no antiproliferative effects after 24 or 48 hours of treatment. Numerous other studies have also examined biodegradable PLGA NPs. Magnetic biodegradable PLGA NPs have been designed for noninvasive cell tracking in vivo by magnetic resonance imaging. ${ }^{28}$ Recent studies on PLGA NPs have shown great potential for utilizing this nanomaterial in various biomedical and biotechnological applications such as cell type recognition, disease diagnosis, and drug/gene delivery. ${ }^{29-33}$ PLGA NPs loaded with ibuprofen have also been used as a model for drug loading and release profiles. ${ }^{34-37}$

Table 2 Release of ibuprofen from PLGA NPs in cells

\begin{tabular}{llll}
\hline Sample & $\begin{array}{l}\text { Ibuprofen } \\
\text { concentration } \\
\text { (ng) }\end{array}$ & $\begin{array}{l}\text { Ibuprofen } \\
\text { (ng/mL) }\end{array}$ & $\begin{array}{l}\text { \% of initially } \\
\text { ibuprofen } \\
\text { added }\end{array}$ \\
\hline Cell lysate after 2 hours & $55.0 \pm 0.01$ & 1100 & 0.3 \\
Cell lysate after 4 hours & $67.5 \pm 0.04$ & 1350 & 0.3 \\
Cell lysate after 24 hours & $75.5 \pm 0.03$ & 1510 & 0.4 \\
\hline
\end{tabular}

Note: Values represent the mean \pm SD of four independent experiments performed in duplicate.

Abbreviations: PLGA, poly(lactic-co-glycolic acid); NPs, nanoparticles.
However, to date, there has been no study on the use of NPs, and in particular, PLGA materials, as carriers of ibuprofen as an antiproliferative drug in vitro or in vivo.

In this study, we used ibuprofen-loaded-PLGA NPs to investigate whether ibuprofen delivered into cells by means of a carrier would exert antiproliferative activity on MKN-45 human gastric cancer cells even at low concentrations. We treated MKN-45 cells with $200 \mu \mathrm{M}$ of free ibuprofen or ibuprofen-loaded PLGA NPs for 24 and 48 hours and noted a dramatic inhibition of the proliferation of cells treated with the latter versus the former. Moreover, the antiproliferative effects were still observed after 48 hours without further addition of NPs. We previously demonstrated the antiproliferative effects of free $400-800 \mu \mathrm{M}$ ibuprofen following the addition of fresh medium containing ibuprofen every day. ${ }^{9}$ However, no significant inhibition was observed with lower concentrations of ibuprofen.

We also treated cells with PLGA NPs, which had no effect on cellular proliferation and were nontoxic to cells. Therefore, the inhibition of proliferation was due to the intracellular release of ibuprofen from the NPs. The percentage of cells that had incorporated fluorescent-loaded ibuprofen 


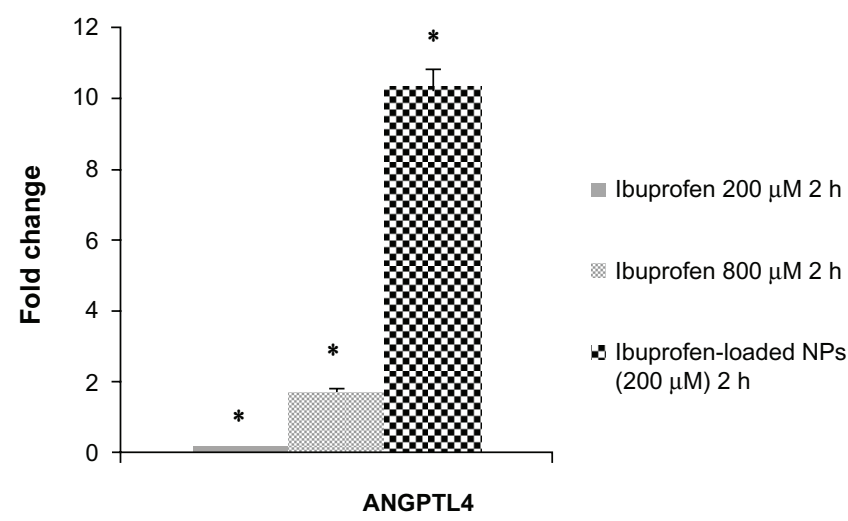

Figure 5 Real-time PCR analysis.

Notes: Analysis of $f$ ANGPTL4 mRNA levels in MKN-45 cells treated with free ibuprofen $(200$ and $800 \mu \mathrm{M})$ or ibuprofen-loaded NPs for 2 hours by Real-Time PCR. Each sample was normalized against human GAPDH. Bars indicate the fold change values versus untreated MKN-45 cells of three independent experiments performed in triplicate. Bars, SD; $* P<0.005$; Student's $t$-test.

Abbreviations: NPs, nanoparticles; GAPDH, human glyceraldehyde 3-phosphate dehydrogenase.

PLGA NPs was $>90 \%$ after 24 hours and remained at these levels after 48 hours. The NPs were already releasing ibuprofen by 2 hours after they were added to the cells; however, only a small concentration $(<1 \mu \mathrm{M})$ of free ibuprofen was detected in the culture medium (data not shown). We have no data on the antiproliferative activity of ibuprofen at such low concentrations. On the other hand, we demonstrated that $200 \mu \mathrm{M}$ ibuprofen had no effect on proliferation of MKN-45 cells at 24 and 48 hours.

We observed the presence of ibuprofen in cell lysates, demonstrating that the NPs released ibuprofen in the cells. The release of a therapeutic agent from PLGA NPs has repeatedly been shown to be biphasic, initially by diffusion through the polymer matrix, and later by diffusion of the therapeutic agent as well as degradation of the polymer matrix itself. ${ }^{38,39}$ Bulk erosion is the main degradation pathway of PLGA copolymers. This process occurs via the random scission of ester bonds in the polymer backbone, randomly throughout the device. ${ }^{40}$ The concentration of released ibuprofen increased rapidly over the first 2 hours and then, increased slowly over time, reaching a maximum at 24 hours. However, the amount of free ibuprofen in cell lysates at 24 hours was approximately $75 \mathrm{ng}$, corresponding to $<1 \%$ of the initially added ibuprofen carried by the PLGA NPs. Once conveyed within the cells, the ibuprofen exerted antiproliferative activity at approximately $5 \mu \mathrm{M} / \mathrm{L}$, a concentration $>100$ times less than that of free ibuprofen, suggesting greater efficiency, and less toxicity to cells. In addition, upregulation of $A N G P T L 4$, a gene involved in proliferation and invasion processes, was triggered by these low concentrations of ibuprofen.
Controlled and targeted delivery of an anticancer agent at the site of action is necessary to maximize the killing effect during the tumor growth phase, and minimize exposure of healthy adjacent cells to the drug, thereby reducing drug toxicity. The success of drug targeting depends on the selection of the targeting agent, which should be abundant, have high affinity and specificity of binding, and be well suited to chemical modification by conjugation. To target ibuprofen-loaded PLGA NPs specifically to MKN-45 cancer cells, we are currently studying the differential expression of membrane receptors in gastric carcinoma cells compared with normal cells, to identify surface receptors that are specific to the tumor cells or at least overexpressed on their surfaces, and that may be able to bind specific antibodies, ligands, and/or aptamers to the NPs. Additionally, our studies will aim at identifying membrane receptors on tumor cells of different lineages that are either not expressed or expressed only at low levels on normal cells, in order to be able to target nanoparticle drug carriers specifically to cancer cells.

\section{Conclusion}

The antiproliferative effect of ibuprofen at such low concentrations is considered to be caused by the direct conveyance of the drug into the cells, and its continuous release from NPs. In conclusion, ibuprofen exerted an antiproliferative effect on MKN-45 cells at low concentrations. This effect was achieved using PLGA NPs as carriers of low doses of ibuprofen. These results suggest the potential for enhancing the therapeutic efficacy of ibuprofen as an anticancer drug. In addition, these results suggest that these NPs could be used in combination with other drugs for the treatment of malignancies.

\section{Acknowledgment}

We thank Dr Angela Amoresano for her advice regarding the determination of intracellular ibuprofen concentrations.

\section{Disclosure}

This work was funded by Misura 3.17 POR Campania $2000 / 2006$. The authors declare that they have no conflicts of interest in this work.

\section{References}

1. Kokoska ER, Smith GS, Wolff AB, DeshpandeY, Miller TA. Nonsteroidal anti-inflammatory drugs attenuate epidermal growth factor-induced proliferation independent of prostaglandin synthesis inhibition. $J$ Surg Res. 1999;84(2):186-192.

2. Thun MJ. NSAID use and decreased risk of gastrointestinal cancers. Gasteroenterol Clin North Am. 1996;25(2):333-348.

3. Giardiello FM. NSAID-induced polyp regression in familial adenomatous polyposis patients. Gasteroenterol Clin North Am. 1996;25(2): 349-362. 
4. Barnes CJ, Cameron IL, Hardman WE, Lee M. Non-steroidal antiinflammatory drug effect on crypt cell proliferation and apoptosis during initiation of rat colon carcinogenesis. Br J Cancer. 1998;77(4):573-580.

5. Fratelli M, Minto M, Crespi A, et al. Inhibition of nuclear factorkappaB by a nitro-derivative of flurbiprofen: a possible mechanism for anti-inflammatory and antiproliferative effect. Antioxid Redox Signal. 2003;5(2):229-235.

6. Baron JA. Epidemiology of non-steroidal anti-inflammatory drugs and cancer. Prog Exp Tumor Res. 2003;37:1-24.

7. Langman MJ, Cheng KK, Gilman EA, Lancashire RJ. Effect of anti-inflammatory drugs on overall risk of common cancer: case-control study in general practice research database. BMJ. 2000;320(7250):1642-1646.

8. Wang WH, Huang JQ, Zheng GF, Lam SK, Karlberg J, Wong BC. Non-steroidal anti-inflammatory drug use and the risk of gastric cancer: a systematic review and meta-analysis. J Natl Cancer Inst. 2003;95(23):1784-1791.

9. Bonelli P, Tuccillo FM, Calemma R, et al. Changes in the gene expression profile of gastric cancer cells in response to ibuprofen: a gene pathway analysis. The Pharmacogenomics J. 2011;11(6):412-428.

10. Brigger I, Dubernet C, Couvreur P. Nanoparticles in cancer therapy and diagnosis. Adv Drug Deliv Rev. 2002;54(5):631-651.

11. Wang K, Ruan J, Qian Q, et al. BRCAA1 monoclonal antibody conjugated fluorescent magnetic nanoparticles for in vivo targeted magnetofluorescent imaging of gastric cancer. J Nanobiotechnology. 2011;9:23.

12. Jain KK. Nanotechnology-based drug delivery for cancer. Technol Cancer Res Treat. 2005;4(4):407-416

13. Cengelli F, Grzyb JA, Montoro A, Hofmann H, Hanessian S, JuilleratJeanneret L. Surface-functionalized ultrasmall superparamagnetic nanoparticles as magnetic delivery vectors for camptothecin. Chem Med Chem. 2009;4(6):988-997.

14. Kuo F, Subramanian B, Kotyla T, Wilson TA, Yoganathan S, Nicolosi RJ. Nanoemulsions of an anti-oxidant synergy formulation containing gamma tocopherol have enhanced bioavailability and anti-inflammatory properties. Intl J Pharm. 2008;363(1):206-213.

15. Shive MS, Anderson JM. Biodegradation and biocompatibility of PLA and PLGA microspheres: Adv Drug Deliv Rev. 1997;28(1):5-24.

16. Fournier E, Passirani C, Montero-Menei CN, Benoit JP. Biocompatibility of implantable synthetic polymeric drug carriers: focus on brain biocompatibility. Biomaterials. 2003;24(19):3311-3331.

17. Middleton JC, Tipton AJ. Synthetic biodegradable polymers as orthopedic devices. Biomaterials. 2000;21(23):2335-2346.

18. Wu L, Ding J. In vitro degradation of three-dimensional porous poly(D,L-lactide-co-glycolide) scaffolds for tissue engineering. Biomaterials. 2004;25(27):5821-5830.

19. Budhian A, Siegel SJ, Winey KI. Haloperidol-loaded PLGA nanoparticles: systematic study of particle size and drug content. Int J Pharm. 2007;336(2):367-375.

20. Teixeira M, Alonso MJ, Pinto MM, Barbosa CM. Development and characterization of PLGA nanospheres and nanocapsules containing xanthone and 3-methoxyxanthone. Eur J Pharm Biopharm. 2005;59(3): 491-500.

21. Müller RH, Jacobs C, Kayser O. Nanosuspensions as particulate drug formulations in therapy: Rationale for development and what we can expect for the future. Adv Drug Deliv Rev. 2001;47(1):3-19.

22. Jain RA. The manufacturing techniques of various drug loaded biodegradable poly(lactide-co-glycolide) (PLGA) devices. Biomaterials. 2000;21(23):2475-2490.

International Journal of Nanomedicine

\section{Publish your work in this journal}

The International Journal of Nanomedicine is an international, peerreviewed journal focusing on the application of nanotechnology in diagnostics, therapeutics, and drug delivery systems throughout the biomedical field. This journal is indexed on PubMed Central,

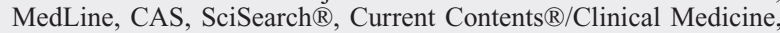

23. Vert M. The complexity of PLGA-based drug delivery systems. In: Proceedings of the International Conference on Advances in Controlled Delivery. Baltimore, MD; 1996:32-36.

24. John-Aryankalayil M, Palayoor ST, Cerna D, Falduto MT, Magnuson SR, Coleman CN. NS-398, ibuprofen, and cyclooxygenase-2 RNA interference produce significantly different gene expression profiles in prostate cancer cells. Mol Cancer Ther. 2009;8(1):261-273.

25. Yoon JC, Chickering TW, Rosen ED, et al. Peroxisome proliferatoractivated receptor gamma target gene encoding a novel angiopoietinrelated protein associated with adipose differentiation. Mol Cell Biol. 2000;20(14):5343-5349.

26. Li KQ, Li WL, Peng SY, Shi XY, Tang HL, Liu YB. Anti-tumor effect of recombinant retroviral vector-mediated human ANGPTL4 gene transfection. Chin Med J (Eng). 2004;117(9):1364-1369.

27. Livak KJ, Schmittgen TD. Analysis of relative gene expression data using real-time quantitative PCR and the 2(-Delta Delta C(T)) Method. Methods. 2001;25(4):402-408.

28. Nkansah MK, Thakral D, Shapiro EM. Magnetic poly(lactide-co-glycolide) and cellulose particles for MRI-based cell tracking. Mag Reson Med. 2011;65(6):1776-1785.

29. Kocbek P, Obermajer N, Cegnar M, Kos J, Kristl J. Targeting cancer cells using PLGA nanoparticles surface modified with monoclonal antibody. J Control Rel. 2007;120(1-2):18-26.

30. Cartiera MS, Johnson KM, Rajendran V, Caplan MJ, Saltzman WM. The uptake and intracellular fate of PLGA nanoparticles in epithelial cells. Biomaterials. 2009;30(14):2790-2798.

31. Yang J, Lee $\mathrm{CH}$, Park J, et al. Antibody conjugated magnetic PLGA nanoparticles for diagnosis and treatment of breast cancer. J Mater Chem. 2007;17:2695-2699.

32. Park J, Fong PM, Lu J, et al. PEGylated PLGA nanoparticles for the improved delivery of doxorubicin. Nanomedicine. 2009;5(4):410-418.

33. Panyam J, Zhou WZ, Prabha S, Sahoo SK, Labhasetwar V. Rapid endo-lysosomal escape of poly(DL-lactide-co-glycolide) nanoparticles: implications for drug and gene delivery. FASEB J. 2002;16(10): 1217-1226.

34. Fernández-Carballido A, Herrero-Vanrell R, Molina-Martínez IT, Pastoriza P. Sterilized ibuprofen-loaded poly(D,L-lactide-co-glycolide) microspheres for intra-articular administration: effect of gammairradiation and storage. J Microencapsul. 2004;21(6):653-665.

35. Fernández-Carballido A, Herrero-Vanrell R, Molina-Martínez IT, Pastoriza P. Biodegradable ibuprofen-loaded PLGA microspheres for intraarticular administration. Effect of Labrafil addition on release in vitro. Int J Pharm. 2004;279(1-2):33-41.

36. Klose D, Siepmann F, Elkharraz K, Siepmann J. PLGA-based drug delivery systems: importance of the type of drug and device geometry. Int J Pharm. 2008;354(1-2):95-103.

37. Pang J, Luan Y, Li F, Cai X, Du J, Li Z. Ibuprofen-loaded poly(lacticco-glycolic acid) films for controlled drug release. Int J Nanomedicine. 2011;6:659-665.

38. Panyam J, Dali MM, Sahoo SK, et al. Polymer degradation and in vitro release of a model protein from poly(D,L-lactide-co-glycolide) nano- and microparticles. J Control Release. 2003;92(1-2):173-187.

39. Barratt GM. Therapeutic applications of colloidal drug carriers. Pharm Sci Technolo Today. 2000;3(5):163-171.

40. Bala I, Hariharan S, Kumar MN. PLGA nanoparticles in drug delivery: the state of the art. Crit Rev Ther Drug Carrier Syst. 2004;21(5): $387-422$.

\section{Dovepress}

Journal Citation Reports/Science Edition, EMBase, Scopus and the Elsevier Bibliographic databases. The manuscript management system is completely online and includes a very quick and fair peer-review system, which is all easy to use. Visit http://www.dovepress.com/ testimonials.php to read real quotes from published authors. 